\title{
Erratum to: Clinical Guide to Accelerated Orthodontics
}

\author{
Mani Alikhani
}

\section{Erratum to:}

M. Alikhani (ed.), Clinical Guide to Accelerated Orthodontics,

DOI 10.1007/978-3-319-43401-8

The following names were incorrect in the previous edition, and it is updated in this current edition: Chinapa Sangsuwon, Mohammed Al Jearah, Miang Chneh Teo

The online version of the original book can be found under DOI 10.1007/978-3-319-43401-8

M. Alikhani

Consortium for Translational Orthodontic Research, Hoboken, NJ, USA

Department of Biology, Harvard School of Dental Medicine, Boston, MA, USA

Department of Applied Oral Sciences, The Forsyth Institute, Cambridge, MA, USA 